Available online at www.jmle.org

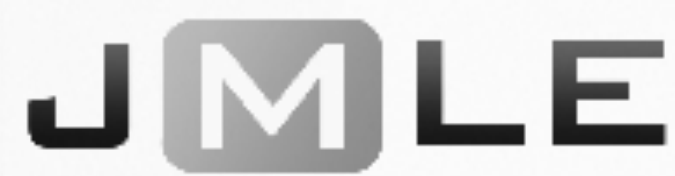

The National Association for Media Literacy Education's

Journal of Media Literacy Education 9 (1), 22 - 35

\title{
Towards a Culturally Inclusive, Integrated, and Transdisciplinary Media Education Curriculum: Case Study of an International MA Program at the University of Lapland
}

\author{
Paivi Rasi \\ Heli Ruokamo \\ Mari Maasiita \\ University of Lapland, Finland
}

\begin{abstract}
Internationalization presents both opportunities and challenges for higher education policies and curricula, as well as for teaching and learning methods. This article describes and discusses ongoing exploration and development of the planned curriculum of the MA in Media Education at the Faculty of Education at the University of Lapland, Finland in terms of cultural inclusion and the integration of disciplines. The study concludes that the planned curriculum now includes new content that better supports cultural inclusion. Nevertheless, it was established that several steps are needed to move toward a more inter- and even transdisciplinary media education higher education curriculum.
\end{abstract}

KEYWORDS: media education, instructional program, university, integrated curriculum, interdisciplinary. curriculum, transdisciplinary, cultural diversity, Finland

Internationalization presents both opportunities and challenges for higher education policies and curricula, as well as for teaching and learning methods. Previous research has indicated several barriers that may hinder students' reciprocal peer-to-peer learning and interaction, as well as learning between international students and academic staff (Kim 2011; Ryan and Viete 2009; McClure 2007). Leask (2009) defined internationalization as "the incorporation of an international and intercultural dimension into the content of the curriculum as well as the teaching and learning methods and support services of a program of study" (p. 209). However, the practical aspects of curriculum internationalization 
have caused confusion, and research on this issue remains relatively scarce (Leask 2013; Clifford 2010).

Another challenge faced by higher education curricula and teaching practices is to support the development of what have typically been framed as "twenty-first century skills" in students. Because of globalization, and the increasing complexity of associated social and environmental problems and labor market changes, there is growing demand for the skills of critical thinking, problem solving, creativity, communication and collaboration (Partnership for 21st Century Skills 2007). These skills needs have typically been addressed through interdisciplinary curricula and interdisciplinary learning, designed to better prepare students to tackle complex problems in interdisciplinary work teams in various fields (Barnard et al. 2013; Pharo et al. 2012). The concept of the integrated curriculum has also been used to describe and discuss multi-, inter-, and transdisciplinary approaches to integrating subjects or disciplines within a curriculum (Drake and Burns 2004).

In the present article, we will discuss ongoing exploration and development of the curriculum of an international media education program: the MA in Media Education (MAME) in the Faculty of Education at the University of Lapland (UoL), Finland. This study examines the planned curriculum in terms of cultural inclusion and integration of disciplines, building on a previous case study of the program (Rasi et al. 2015). The previous study examined the 2012-2014 MAME curriculum's level of cultural inclusion by asking How do the planned and experienced curricula respond to and support cultural inclusion? The term "planned curriculum" referred to the knowledge, goals, and objectives deemed important by the curriculum designers and written into the curriculum; the concept of "experienced curriculum" refers to media education students' experiences of the curriculum (Marsh 2009).

In the present study, we $\mathrm{e}^{1}$ explore the 2015-2016 planned curriculum to establish whether it has been successfully redesigned for greater culturally inclusion. Second, we analyze the planned curriculum in terms of how it integrates a range of disciplines. Before describing our analysis and its results, we will briefly explain what we mean by a culturally inclusive and integrated media education curriculum in the context of higher education.

\section{Cultural Inclusion, Multiculturalism, and Diversity within the Curriculum}

Here, the term "cultural inclusion" is used to refer to the principles of inclusive education, including access and equity for all students and a dynamic process of inclusionary and exclusionary pressures in all learning settings (UNESCO 2012). This concept highlights structural conditions that affect presence, participation, and achievement in various educational institutions, shaped by the curriculum and teaching and learning methods. Previous studies indicate a need to enhance the cultural inclusiveness of curricula and practices, and suggest that cultural diversity is often an underused resource (Guo and Chase 2011; Bond 2003). In the case of international study programs, student diversity

\footnotetext{
${ }^{1}$ All three authors currently teach in the MAME program.

${ }^{2}$ The curriculum is partly available online: http://www.ulapland.fi/InEnglish/Units/Centre-for-
} 
should be viewed as enriching the learning environment. Understood as a resource for teaching and learning, cultural diversity offers students and teachers opportunities for more varied and challenging learning experiences, leading to the exchange of ideas and knowledge, and offering new directions for personal and societal development (Wubbels et al. 2008).

Developing a study program that is both truly international and culturally inclusive and diverse is challenging in a globalizing world. As curricula are always culturally determined and shaped by environmental, scientific, economic, and political factors within a given society, many viewpoints and perspectives are inevitably excluded from the curriculum, however relevant these may be in students' native contexts (Kellner 1998). Rather than the more common term "curriculum philosophy," Schiro (2013) uses the concept of "curriculum ideology" to refer to the motives that underlie behavior and articulated beliefsin this case, the planned curriculum - encompassing the collected ideas, visions, myths, doctrines, opinions, worldviews, conceptual frameworks, and belief systems that motivate and inform curriculum designers. Following Schiro (2013), it is important to acknowledge that "educators dealing with curriculum are often not conscious of the major assumptions underlying their actions" (p. 10). As teachers, we understand the role of critical curriculum analysis as a step in better understanding the assumptions that inform our work.

In terms of cultural inclusion, one finding of the previous case study on the MAME program (Rasi et al. 2015) was that some international students experienced a mismatch between the knowledge gained from the MAME program and the application of that knowledge to their present or future life-world. One student was concerned that she might not be able to apply that critical academic knowledge in her country of origin because of the local political system's control of the media. Her experience of returning home with her newly gained knowledge to work as a journalist was somewhat problematic, as she was not free to do what she thought of as "good." Taking such differences in students' life-worlds into account is important in shaping how "international," "multicultural," or "diverse" is to be understood in the context of a curriculum. International programs must therefore be built around recognizing and respecting differences rather than imagining some shared set of values and goals.

\section{Integration of Disciplines Within the Curriculum}

Media education is commonly understood to be multidisciplinary in nature, drawing theoretically and methodologically on such fields as the educational sciences, social sciences, humanities, and information sciences (Kupiainen et al. 2008). The multidisciplinary nature of media education is apparent in how media education studies and programs in higher education contexts are coordinated and situated in faculties and schools. For example, in Finland, in the context of this study, media education can be studied as a major in two universities, both offering international master's programs. At the University of Lapland, the master's program is situated in the Faculty of Education, whereas at the University of Tampere, the program is coordinated by the School of Communication, Media and Theatre, in cooperation with the School of Education. 
It is important to understand what the term multidisciplinary actually means. Multidisciplinary research (multi- $=$ combining or crossing many or multiple) combines parallel, purposive work in many different disciplines. Multidisciplinary teams do not necessarily work in close collaboration but benefit from each other's perspectives. This may lead to situations in which a research topic is addressed from various angles of observation, without necessarily achieving an integrated or interactive whole. As multidisciplinary team members all represent their own fields of expertise, which they seek to highlight, the whole may not be fully or equitably constituted, leading in turn to biased final results (Ruokamo and Tella 2005). In curriculum terms, multidisciplinary integration of disciplines can mean, for example, organizing the curriculum as well as related teaching and learning methods around a common theme, phenomenon, or problem, which each discipline explores from its own viewpoint rather than interacting with other disciplines (see for example Drake and Burns 2004). Multidisciplinary curricula and teaching approaches do not inevitably entail the synthesis of knowledge and methodologies drawn from various disciplines but may instead incorporate disciplines as non-interactive parallels (see Yang 2009).

In some cases, media education is defined as interdisciplinary research, conducted within diverse disciplines such as social sciences, humanities, and the arts (Pekkala et al. 2013). Interdisciplinary research (inter- = between, among, or shared by) makes a point of using the methods and concepts of two or more disciplines and arts in order to solve problems, and interdisciplinary teams always comprise experts from several disciplines. Such teams work in close contact and compare their thinking systematically and regularly. Communication between interdisciplinary teams and among their members is characterized by frequent use of tools, methods, and instruments that encourage information sharing (Ruokamo and Tella 2005). In the present context, one way to construct an interdisciplinary curriculum is to bring together the common areas of inquiry within the various disciplines so that interdisciplinary skills and concepts are emphasized while disciplines remain distinct (Drake and Burns 2004). Students can benefit from interdisciplinarity through the integration of knowledge, understanding, methodologies, and perspectives from multiple disciplines (Yang 2009). Pharo et al. (2012) characterized interdisciplinarity as the integration of disciplinary perspectives to produce insights that are more than the summing of disciplinary knowledge. Based on her literature review, Nikitina (2006) argued that a distinction between multi-, inter-, and transdisciplinary is often based on how closely the disciplines bond in the interaction; what is produced as a result of this bonding is an overarching synthesis of the various disciplinary viewpoints. In terms of curriculum and related teaching practices, one strategy for interdisciplinarity is problem-centering (Nikitina 2006), realized through pedagogical approaches such as problem-based learning, project-based learning, and case-based learning (Savin-Baden 2007; Yang 2009).

Media education is only rarely defined as transdisciplinary in nature. Transdisciplinary research (trans- $=$ across, beyond, through or changing) crosses scientific boundaries to deliberately and purposefully overcome the limitations of multiple disciplines in terms of research methodologies, themes, and the research 
teams themselves. In their communication, interaction, and other activities, transdisciplinary teams seek in particular to ensure that the different fields interact synergistically at all times. In transdisciplinary teams, members are more closely interdependent than those of multi- and interdisciplinary teams, who retain more individual autonomy. In transdisciplinary teams, then, individuals must deliberately commit themselves to the aims and goals of the team, helping and supporting each other on an ongoing basis (Ruokamo and Tella 2005). Some researchers understand the transdisciplinary curriculum to be organized around students' questions and concerns, promoting the development of students' life skills as they apply interdisciplinary skills in real-life contexts and to problems that are meaningful for them. For example, in project-based learning, students may tackle a local problem based on their interests, curriculum standards, and local resources, and in consequence, the boundaries between disciplines may gradually dissolve (Drake and Burns 2004).

However, in inter- and transdisciplinary programs, students need support in tackling complex issues and problems. For example, Pharo and others (2012) described an interdisciplinary teacher collaboration in which, "rather than leaving it to students to piece together disciplinary responses, eight teaching academics collaborated on the task of exposing students to different types of knowledge in a way that was more than the summing of disciplinary parts" (p. 497). In a similar vein, Chen, Hsu and Wu (2009) underlined the importance of the instructor's role in explicating the interrelationships among concepts in different disciplines to avoid excessive cognitive load.

\section{Research Setting, Data and Methodology}

This section will describe the approach taken in addressing the following two research questions: (1) Has the planned MAME curriculum for 2015-2016 been redesigned to become more culturally inclusive, and if so, how? (2) How does the planned 2015-2016 MAME curriculum integrate various disciplines?

The research setting is the University of Lapland (UoL), which is the northernmost university in Finland (and in the European Union). In 2013, it had a population of 4,240 full-time graduate students, 338 postgraduate students, 132 international graduate and postgraduate students, and 268 incoming exchange students; the UoL Internationalization Programme (Lapin yliopisto 2012) set a slightly higher target for the years 2013-2016. The MAME program, which opened in 2010, has an annual intake of 10 international students. Although the medium of instruction at the UoL is generally Finnish, the MAME program is taught through English. The program prepares students for careers as experts in fields such as educational planning, adult education, administration, policymaking and supervision, public communication, project management, and academic research. The teaching staff of the MAME program come from various backgrounds, including education, adult education, journalism and mass communication, and social psychology.

The 120 credits of the MAME curriculum include three courses, each attracting 5 ECTS (European Credit Transfer and Accumulation System) that are mandatory for all students: Research on Media Education, Internet Use and 
Psychosocial Well-Being, and Approaches to Media Culture. In addition, students are expected to take elective courses or book exams worth 10 ECTS from other courses offered by the Faculty or by the wider University. A three-month practical training period (10 ECTS), comprising training and a reflective essay, is included in the curriculum. In addition, students are expected to take four research methodology courses (20 ECTS). Finally, during their second or third year, students must write their master's thesis (30 ECTS), supported by a research seminar (10 ECTS) that spans the whole academic year. Bridging Studies courses (25 ECTS) are provided for students with no prior knowledge of media education.

The Bridging Studies (25 ECTS) consist of the following courses: Introduction to Global Media Education (5 ECTS), Theoretical Approaches to Media Use and Psychosocial Well-Being (5 ECTS), Critical Media Analysis (5 ECTS), Media Educator in Working Life (5 ECTS) and Pedagogical Models for Educational Use of ICTs (5 ECTS). In practice, most of the international students take the Bridging Studies courses, as media education bachelor studies are offered in only a few universities (either in Finland or internationally).

For our study of the planned curriculum (Marsh 2009), we collected data based on the MAME program curriculum for the years 2015-2016. Curriculum documents were analyzed using qualitative content analysis, taking into account how the course content, learning objectives, teaching and learning methods and resources respond to and support cultural inclusion, with regard to the various cultural backgrounds of students and integration of the various disciplines.

\section{Results}

\section{Cultural Inclusion in the MAME Curriculum}

The previous study (of the planned MAME curriculum for the years 20122014) identified structural conditions that negatively affected cultural inclusion and suggested how the curriculum might be redesigned and refined (Rasi et al. 2015). First, instead of meeting the ideals of cultural inclusion and openness, the prescribed texts and books interpreted "international" mainly in terms of Englishlanguage texts and Anglo-American culture in general. The analysis indicated that the curriculum did not sufficiently provide for learning about media education from a domestic (in this case, Finnish) perspective. The prescribed books and other texts play an important role in forming the program's cultural context. From the point of view of cultural diversity, it is essential that the curriculum emphasizes contributions by people from various cultures (Nelson Laird 2011). The cultural diversity of the planned curriculum can be evaluated in terms of the books and texts proposed as study material.

Second, while intercultural interaction was written into the planned curriculum in the form of collaborative teaching and learning methods described as "reciprocal teaching," "collaborative learning," "case-based teaching," and "reflective collaborative seminars," the experienced curriculum indicated that students' intercultural interaction with peers, experts and other stakeholders remained a somewhat unused asset. The previous study also identified challenges related to the three-month practical training period. International students reported 
difficulties in finding internships in domestic businesses and organizations because of their insufficient Finnish language skills or because media education is not yet a well-established field outside academia (Rasi et al. 2015). These issues are especially alarming, as many international students hope to stay in Finland and to integrate into Finnish working-life after graduating but face challenges because of their lack of knowledge about the requirements and standards of Finnish working life.

To address the aforementioned challenges related to cultural inclusion, two new courses were designed into the 2015-2016 curriculum: Introduction to Global Media Education (5 ECTS) and Media Educator in Working Life (5 ECTS). The curriculum states that the goal of the Introduction to Global Media Education is for students to "get acquainted with theories and practices of media education in different cultural contexts." To balance the bias toward books written by scholars from US and UK institutions in the previous curriculum (Rasi et al. 2015), readings and web resources from Finnish media education institutions, Nordic academic institutions, along with one web resource published by UNESCO are included in the new 2015-2016 curriculum. However, the teachers of both of these courses (as well as the MAME program) are all Finnish, and there are no contributions by teachers from other cultural contexts.

Looking at the lists of proposed supplementary literature in the MAME curriculum, twelve books or book chapters, four articles and six web-based resources were listed in the curriculum. In addition, students could choose an optional book exam related to their own master's thesis research. This element listed three optional sets of books and scientific journals, as shown on Table 1), from which the students can choose one set to study independently for the exam. Within these options, twelve scientific journals and nine books were listed in total; the visible bias toward books written by scholars from US and UK institutions indicated by previous research into the MAME curriculum (Rasi et al. 2015) was still evident. However, it should also be noted that the content within these books and journals was more diverse than could be judged from the publisher, and several books included authors from non-Anglo American societies. Some also included articles dealing with ethnic, racial, and gendered diversity in Western societies, and some others concentrated on cultural contexts beyond Europe and the United States.

At least in principle, a practical training period makes it possible to integrate international students into the Finnish labor market, and to this end, a new course, entitled Media Educator in Working Life (5 ECTS) was designed. The curriculum states that on completing the course, the student "knows the working field of media educators in Finland and internationally," "understands her/his professional role in working life and is able to reflect his/her professional knowledge, skills and capacities as media educator," and "is able to plan and orientate one's own studies towards the needs of working-life." To familiarize students with working practices, the course is implemented in close cooperation with local media educators, whom students meet and interview, as well as visiting media education institutions. 
Table 1

Examples of the thematic media education literature in MAME program's curriculum

\begin{tabular}{|c|c|}
\hline Theme & Literature \\
\hline Media in Teaching and Learning & $\begin{array}{ll}\text { - } & \text { Australasian Journal of Educational Technology } \\
\text { - } & \text { Educational Researcher } \\
\text { - } & \text { Educational Technology \& Society } \\
\text { Seminar.net - International Journal of Media, Technology and Lifelong Learning }\end{array}$ \\
\hline Media in Society & $\begin{array}{l}\text { - } \quad \text { Everett, A. 2008. Youth and digital media. The John D. and Catherine T. MacArthur Foundation } \\
\text { - } \quad \text { Geries on Digital Media and Learning. Cambridge, MA: The MIT Press. } \\
\text { - } \quad \text { McMillin, D.C. 2007. International media studies. Malden (Mass.): Blackwell. } \\
\text { - } \quad \text { McPherson, T. (Ed.) 2008. Digital youth, innovation, and the unexpected. The John D. and Catherine } \\
\text { T. MacArthur Foundation Series on Digital Media and Learning. Cambridge, MA: The MIT Press. } \\
\text { - } \quad \text { McRobbie, A. 2009. The aftermath of feminism, gender, culture, and social change. London: Sage. } \\
\text { - } \quad \text { Olsson, T. \& Dahlgren 2010. Young people, ICTs and democracy. Gothenbourg: Nordicom. } \\
\text { - Salen, K. (Ed.) 2008. The ecology of games: Connecting youth, games, and learning. The John D. } \\
\text { and Catherine T. MacArthur Foundation Series on Digital Media and Learning. Cambridge, MA: The } \\
\text { - MIT Press. } \\
\text { - Stokes, J. 2003. How to do media \& cultural studies. London: Sage. } \\
\text { Tufte, T., Wildermuth, N., Hansen-Skovmoes, A-S. \& Mitullah, W. 2013. Speaking up and talking } \\
\text { back? University of Gothenburg: Nordicom. }\end{array}$ \\
\hline $\begin{array}{l}\text { Media and Psychosocial } \\
\text { Well-Being }\end{array}$ & $\begin{array}{ll}\text { - } & \text { Computers in Human Behavior } \\
\text { - } & \text { New Media \& Society } \\
\text { - } & \text { Journal of Computer-Mediated Communication } \\
\text { - } & \text { Cyberpsychology: Journal of Psychosocial Research on Cyberspace } \\
\text { - } & \text { International Journal of Human-Computer Studies } \\
\text { - } & \text { Journal of Social and Personal Relationships } \\
& \text { Journath and Adolescence }\end{array}$ \\
\hline
\end{tabular}

\section{Integration of Disciplines in the MAME Program}

The disciplinary orientations within the MAME program are apparent in the three themes that the curriculum builds on. ${ }^{2}$ These multidisciplinary themes relate to the scientific backgrounds of the teaching staff, who plan the curriculum collaboratively with the aim of providing students with various disciplinary viewpoints. These themes also reflect the understanding of the scope and aims of media education shared by the curriculum designers - that is, as a field of science that seeks a deeper understanding of the meanings of media in teaching and learning, in civic society and empowerment, and in the well-being of individuals and communities. The first theme, Media in Teaching and Learning, is most clearly connected to education, and is taught by staff with $\mathrm{PhDs}$ in educational sciences (education, adult education, media education). The second theme, Media in Society, relates to social sciences, and is taught by a member of staff with a $\mathrm{PhD}$ in social sciences (journalism and mass communication). The third and final theme, Media and Psychosocial Well-Being, relates to the disciplines of social

\footnotetext{
${ }^{2}$ The curriculum is partly available online: http://www.ulapland.fi/InEnglish/Units/Centre-forMedia-Pedagogy/Studying/MA-in-Media-Education
} 
psychology and psychology, and is taught by a member of staff who is currently finishing her $\mathrm{PhD}$ in social sciences (social psychology). Theme descriptions and the examples of courses offered within each theme are provided in Table 2.

Table 2

Themes, courses, and main disciplinary emphases within the MAME curriculum

\begin{tabular}{|c|c|c|c|}
\hline Theme & Description of the theme & Courses offered & $\begin{array}{l}\text { Main disciplinary } \\
\text { emphasis }\end{array}$ \\
\hline $\begin{array}{l}\text { Media in Teaching and } \\
\text { Learning }\end{array}$ & $\begin{array}{l}\text { In this theme students get acquainted with how media as } \\
\text { well as information and communication technology (ICT) } \\
\text { can be utilised in teaching and learning processes. This is } \\
\text { done from the viewpoints of learning theory, } \\
\text { constructivism, and society and culture. The students } \\
\text { examine the use of media and ICT in different formal and } \\
\text { informal learning environment contexts through } \\
\text { production, reception, and critical observation. The goal } \\
\text { is that the students are able to utilise media and ICT in a } \\
\text { pedagogically appropriate manner. They also are familiar } \\
\text { with a variety of pedagogical models and methods for } \\
\text { using ICT in teaching and learning. The students also } \\
\text { learn methods for online guidance and tutoring. They will } \\
\text { familiarise themselves with multidisciplinary media } \\
\text { education research and can analyse it critically. }\end{array}$ & $\begin{array}{l}\text { Pedagogical Models in } \\
\text { Educational Use of } \\
\text { Information and } \\
\text { Communication } \\
\text { Technologies } \\
\text { Media Education } \\
\text { Literature: Media in } \\
\text { Teaching and Learning }\end{array}$ & $\begin{array}{l}\text { Educational sciences } \\
\text { (education, adult } \\
\text { education, media } \\
\text { education) }\end{array}$ \\
\hline Media in Society & $\begin{array}{l}\text { In this theme students get acquainted with the role of } \\
\text { media in society and the historical and philosophical } \\
\text { foundations of critical media education. This is done } \\
\text { through the viewpoints of media and cultural studies, } \\
\text { sociology, philosophy, and critical media education. The } \\
\text { students examine the mediatization of society and the role } \\
\text { of media in the society's political, economic, cultural, and } \\
\text { gendered structures. The goal is that the students } \\
\text { understand the role of media in society and are familiar } \\
\text { with theories explaining empowerment, control, and } \\
\text { influence of media. Students are also able to search, read, } \\
\text { and critically analyse research literature dealing with the } \\
\text { role of media in society and the principles of critical } \\
\text { media education. }\end{array}$ & $\begin{array}{l}\text { Critical Media Analysis } \\
\text { Approaches to Media } \\
\text { Culture } \\
\text { Media Education } \\
\text { Literature: Media in } \\
\text { Society }\end{array}$ & $\begin{array}{l}\text { Social sciences } \\
\text { (media and cultural } \\
\text { studies, sociology) }\end{array}$ \\
\hline $\begin{array}{l}\text { Media and Psychosocial } \\
\text { Well-Being }\end{array}$ & $\begin{array}{l}\text { In this theme students get acquainted with the roles of } \\
\text { media in the psychosocial well-being of individuals and } \\
\text { communities. This is done through the viewpoints of } \\
\text { social psychology and psychology. The roles of media in } \\
\text { the psychosocial well-being of people of all ages are } \\
\text { examined especially from the viewpoints of emotional } \\
\text { and cognitive processes, behaviour, identity, social } \\
\text { relations, and communality. The goal is that students are } \\
\text { familiar with theories explaining psychosocial well-being } \\
\text { and media effects, and understand the interactive and } \\
\text { culturally shaped nature of the relationships of } \\
\text { individuals and communities with media. In addition, the } \\
\text { goal is that students are able to search, read, interpret, and } \\
\text { critically analyse research publications dealing with the } \\
\text { topic of media and psychosocial well-being. }\end{array}$ & $\begin{array}{l}\text { Theoretical Approaches } \\
\text { to Media Use and } \\
\text { Psychosocial Well-Being } \\
\text { Internet Use and } \\
\text { Psychosocial Well-Being } \\
\text { Media Education } \\
\text { Literature: Media in } \\
\text { Society }\end{array}$ & $\begin{array}{l}\text { Social sciences (social } \\
\text { psychology, psychology) }\end{array}$ \\
\hline
\end{tabular}


The planned MAME curriculum for 2015-2016 is multidisciplinary in the sense that the separate courses, each instructed by a single teacher, explore their overarching theme mainly from the viewpoint of the scientific field that the course instructor specializes in (Drake and Burns 2004). Within that scientific field, the instructor may of course be integrating viewpoints from several disciplines, but the curriculum as such does not provide evidence of this integration. To assess the multi-, inter-, or transdisciplinary nature of students' learning experiences - that is, the experienced curriculum (Marsh 2009) -we must look to other kinds of research data. Whether the courses listed in Table 2 afford opportunities for interdisciplinary and transdisciplinary learning depends, among other things, on teaching and learning methods, the research orientation of the instructors, and the scientific backgrounds of the students. As MAME program students come from different disciplines, their work with the teaching staff and within their own student teams is both challenging and enriching.

How does the planned curriculum address $21^{\text {st }}$ century skills (Partnership for $21^{\text {st }}$ Century Skills 2007) in students? Looking at the three mandatory courses, critical thinking, communication and collaboration are written into the curriculum through teaching and learning methods in which students' role is to analyze and discuss scientific literature and real-life cases (Table 3). However, students' problem-solving skills and creativity are not explicitly addressed in the planned curriculum. Problem-centering (Nikitina 2006) and pedagogical approaches such as problem-based learning and project-based learning (see for example SavinBaden 2007; Yang 2009) are not written into the curriculum with the exception of one course that draws on case-based teaching. Within the Bridging Studies (25 ECTs), two course descriptions explicitly address $21^{\text {st }}$ century skills, as the descriptions (Table 3) state that the courses aim at developing students' skills in critical media analysis and practical application of theoretically grounded pedagogical models.

From the viewpoint of curriculum and staff development and student learning, interdisciplinary teacher collaboration has yielded promising results in higher education contexts (Pharo et al. 2012). The MAME curriculum for 20152016 includes two introductory courses (Introduction to Global Media Education and Introduction to Media Education) that are co-taught by teachers from several disciplines. However, these teachers are not engaged in simultaneous co-teaching or dialogue with each other while teaching but rather take turns in running lectures and workshops for students. Help for students in understanding, integrating, or synthesizing the various disciplinary viewpoints, concepts, and methods (Pharo et al. 2012; Yang 2009) is not purposefully written into the curriculum. For example, simultaneous and dialogic co-teaching practices or learning assignments aimed at integrating educational sciences and social sciences are missing from the curriculum, and students must make connections and integrate disciplinary views independently. In these circumstances, it seems likely that the course content as a whole may be less easily constructed and integrated in students' minds (Chen et al. 2009). 
Table 3

Examples of how course descriptions within the MAME curriculum address $21^{\text {st }}$ century skills

\begin{tabular}{|c|c|c|}
\hline & Course offerings & Description of teaching and learning methods addressing $21^{\text {st }}$ century skills \\
\hline \multirow{3}{*}{$\begin{array}{l}\text { Mandatory courses }(15 \\
\text { ECTs) }\end{array}$} & $\begin{array}{l}\text { Research on Media Education } \\
\text { (5 ECTs) }\end{array}$ & $\begin{array}{l}\text { Students read and analyze Doctoral Theses and reviewed journal articles that are } \\
\text { within the field of media education. }\end{array}$ \\
\hline & $\begin{array}{l}\text { Internet Use and } \\
\text { Psychosocial Well-Being } \\
(5 \text { ECTs) }\end{array}$ & $\begin{array}{l}\text { Students will construct, read and discuss real-life cases relating to the course } \\
\text { topics in small groups. The course draws on case-based teaching and includes } \\
\text { lectures, and students' case presentations and discussions. }\end{array}$ \\
\hline & $\begin{array}{l}\text { Approaches to Media Culture } \\
\text { (5 ECTs) }\end{array}$ & $\begin{array}{l}\text { The course focuses on research traditions examining media structures, media } \\
\text { influences, media psychology, media and democracy, audience, popular and } \\
\text { visual culture, gender and new media. The lectures are interactive by their nature } \\
\text { and require participation in the discussion as well as in the exercises to be } \\
\text { performed during the lectures. }\end{array}$ \\
\hline \multirow[t]{2}{*}{$\begin{array}{l}\text { Bridging Studies } \\
(25 \text { ECTs) }\end{array}$} & $\begin{array}{l}\text { Critical Media Analysis } \\
\text { (5 ECTs) }\end{array}$ & $\begin{array}{l}\text { Through lectures, course readings and exercises course aims at developing } \\
\text { students' skills in critical media analysis. The course provides the students with } \\
\text { different theoretical, methodological and conceptual tools in exercising critical } \\
\text { analysis of media texts, production, consumption and reception. }\end{array}$ \\
\hline & $\begin{array}{l}\text { Pedagogical Models for } \\
\text { Educational Use of ICTs } \\
(5 \text { ECTs })\end{array}$ & $\begin{array}{l}\text { Students familiarize themselves with research-based and theoretically well- } \\
\text { grounded pedagogical models and plan how to use them in practice. }\end{array}$ \\
\hline
\end{tabular}

As well as teaching and learning methods, another key affordance for inter- and transdisciplinary curricula is a practical training period for students. Previous research has indicated a change in some higher education students' perceptions of interdisciplinary curriculum content over time, as students nearing graduation have reported a greater appreciation of interdisciplinary education in preparing them for the world of work after completing their practical training/placement (Barnard et al. 2013). Such a practical training period clearly offers students opportunities to reflect on complex issues, problems, and phenomena from multiple disciplinary viewpoints, and to integrate and synthesize these viewpoints. However, these opportunities must be designed and written into the curriculum in the form of, for example, interdisciplinary learning assignments and teacher collaborations.

Transdisciplinarity represents a challenge for the MAME curriculum. The interactivity and integration of various disciplines is best fulfilled through communal and shared interaction. As mentioned earlier, this would require staff to engage in simultaneous co-teaching and facilitating, as for instance in research seminars and supervision of practical training. Transdisciplinary teams also commonly include experts from neighboring fields of science or domains of knowledge, which is likely to lead to a sharing of roles that differs somewhat from interdisciplinary teams. This is something we would hope to achieve in planning and implementing our forthcoming media education curriculum for 2017-2019. 


\section{Conclusion}

From our preliminary analysis of the planned curriculum, it is clear that while we may have succeeded in designing a multi- and interdisciplinary curriculum, we need to take several further steps to arrive at a more interdisciplinary or transdisciplinary higher education curriculum for media education. There is also a need to better involve students in the process of curriculum development, as previous research indicates that students' learning experiences and their interest in interdisciplinary study are influenced by their involvement in that process (Chen et al. 2009). Our next steps in this regard will be to design curriculum content, interdisciplinary teacher collaborations and teaching methods that support the interaction, integration and synthesis of the multiple educational and social sciences encompassed by the MAME curriculum.

Developing a study program that is both truly international and culturally inclusive is challenging. Internationalization of the curriculum content and teaching and learning methods (Leask 2009) entails promoting cultural inclusion and the integration of disciplines, since in a globalizing world, students need to tackle complex issues and problems. The best way to co-construct our knowledge, in close collaboration with each other and our students, would be to co-teach and solve complex problems together. Presently, students' problem-solving skills and creativity are not explicitly addressed in the planned curriculum.

The development of online learning technologies support the internationalization of the curriculum. Educational technologies have made possible the growth of international collaborative university partnerships such as MOOCs and online courses (University of Oxford 2015). However, with the exception of short-term visiting lecturers, the teachers in our program are all Finnish, and in this regard, our next steps include seeking opportunities for building international, inter-university online courses or course contents. Our new course Introduction to Global Media Education provides one opportunity to accomplish this as we could invite teachers beyond Finland to teach the course with us.

Certainly, we agree with Chen, Hsu and Wu's (2009) argument that curriculum reform is "definitely not a one-off process" (172). One obvious limitation of our present analysis is that it focuses only on the planned curriculum rather than on both the planned and the experienced curriculum. Once a sufficient number of students have studied the new curriculum for at least one academic year, we will gather data from students' experiences (i.e., the experienced curriculum) as well.

\section{References}

Barnard, Sarah, Tarak Hassan, Andrew Dainty, and Barbara Bagilhole. 2013. "Interdisciplinary Content, Contestations of Knowledge and Informational Transparency in Engineering Curriculum." Teaching in Higher Education 18(7): 748-760.

Bond, Sheryl. 2003. Untapped Resources, Internationalization of the Curriculum and Classroom Experience: A Selected Literature Review. Ottawa: Canadian Bureau for International Education. 
Chen, Sufen, Ian C. Hsu, and Chien-Ming Wu. 2009. "Evaluation of Undergraduate Curriculum Reform for Interdisciplinary Learning." Teaching in Higher Education 14(2): 161-173.

Clifford, Valeria. 2010. "The Internationalised Curriculum. (Dis)locating Students." In Internationalisation and the Student Voice. Higher Education Perspectives, edited by Elspeth Jones, 169-180. New York: Routledge.

Drake, Susan M., and Rebecca C. Burns. 2004. Meeting Standards Through Integrated Curriculum. Alexandria, VA: Association for Supervision and Curriculum Development.

Guo, Shibao, and Mackie Chase. 2011. "Internationalisation of Higher Education: Integrating International Students into Canadian Academic Environment." Teaching in Higher Education 16(3): 305-318.

Kellner, Douglas. 1998. "Multiple Literacies and Critical Pedagogy in a Multicultural Society." Educational Theory 48(1): 103-122.

Kim, Hye Yeong. 2011. 'International Graduate Students' Difficulties: Graduate Classes as a Community of Practices." Teaching in Higher Education 16(3): 281-292.

Kupiainen, Reijo, Sara Sintonen, and Juha Suoranta. 2008. Decades of Finnish Media Education. Publications of the Finnish Association on Media Education. Accessed May 23, 2016. http://www.mediakasvatus.fi/wpcontent/uploads/2014/11/decadesoffinnishmediaeducation.pdf.

Lapin yliopisto. 2012. Lapin yliopiston kansainvälisyysohjelma 2013-2016 [University of Lapland Internationalization Program). Accessed May 23, 2016. http://www.ulapland.fi/loader.aspx?id=2603cf12-1880-4122-9a3b$08292624 \mathrm{e} 01 \mathrm{c}$

Leask, Betty. 2009. "Using Formal and Informal Curricula to Improve Interactions between Home and International Students." Journal of Studies in International Education 13(2): 205-221.

Leask, Betty. 2013. "Internationalizing the Curriculum in the DisciplinesImagining New Possibilities." Journal of Studies in International Education 17(2): 103-118.

Marsh, Colin J. 2009. Key Concepts for Understanding Curriculum (4th ed.). London: Routledge.

McClure, Joanne W. 2007. 'International Graduates' Cross-Cultural Adjustment: Experiences, Coping Strategies, and Suggested Programmatic Responses." Teaching in Higher Education 12(2): 199-217.

Nelson Laird, Thomas F. 2011. "Measuring the Diversity Inclusivity of College Courses." Research in Higher Education 52(6): 572-588.

Nikitina, Svetlana. 2006. "Three Strategies for Interdisciplinary Teaching: Contextualizing, Conceptualizing, and Problem-Centring." Journal of Curriculum Studies 38(3): 251-271.

Partnership for 21st Century Skills. 2007. Framework for 21st Century Learning. Accessed June 23, 2016. http://www.p21.org/our-work/p21-framework

Pekkala, Leo, Saara Pääjärvi, Lauri Palsa, Saana Korva, and Anu Löfgren. 2013. Media Education Research in Finland: A Literature Review. A Review of 
Finnish Research Literature on Media Education, in Particular Academic Theses and Peer-Reviewed Articles in Academic Journals, mostly Dating from 2007 to 2012. Helsinki, Finland: Finnish Centre for Media Education and Audiovisual Media.

Pharo, Emma J., Aidan Davison, Kristin Warr, Melissa Nursey-Bray, Kim Beswick, Erik Wapstra, and Colin Jones. 2012. "Can Teacher Collaboration Overcome Barriers to Interdisciplinary Learning in a Disciplinary University? A Case Study Using Climate Change.” Teaching in Higher Education 17(5): 497-507.

Rasi, Päivi, Mikko Hautakangas, and Sai Väyrynen. 2015. "Designing Culturally Inclusive Affordance Networks into the Curriculum." Teaching in Higher Education 20(2): 131-142.

Ryan, Janette, and Rosemary Viete. 2009. "Respectful Interactions: Learning with International Students in the English-Speaking Academy." Teaching in Higher Education 14(3): 303-314.

Ruokamo, Heli, and Seppo Tella. 2005. "An M+I+T++ Research Approach to Network-Based Mobile Education (NBME) and Teaching-StudyingLearning Processes: Towards a Global Metamodel.” In The IPSI BgD Transactions on Advanced Research: Multi-, Inter-, and Transdisciplinary Issues in Computer Science and Engineering. Special Issue on the Research with Elements of Multidisciplinary, Interdisciplinary, and Transdisciplinary: New York, Frankfurt, Tokyo, Belgrade. IPSI BgD Internet Research Society 1(2): 3-12.

Savin-Baden, Maggi. 2007. "Challenging Models and Perspectives of ProblemBased Learning." In Management of Change: Implementation of ProblemBased and Project-Based Learning in Engineering, edited by Erik de Graaff, and Anette Kolmos, 9-29. Rotterdam: Sense Publishers.

Schiro, Michael Stephen. 2013. Curriculum Theory: Conflicting Visions and Enduring Concerns (2nd ed.). Los Angeles: Sage Publications.

UNESCO. 2012. Addressing Exclusion in Education. A Guide to Assessing Education Systems Towards More Inclusive and Just Societies. Paris: UNESCO.

University of Oxford. 2015. International Trends in Higher Education 2015. University of Oxford International Strategy Office. Accessed October 15, 2016.

https://www.ox.ac.uk/sites/files/oxford/International\%20Trends\%20in $\% 2$ 0Higher\%20Education\%202015.pdf

Wubbels, Theo, Perry J. den Brok, Ietje M.J. Veldman, and Jan W.F. van Tartwijk. 2008. "Teacher Professionalism in Multicultural Classrooms: Specific or Generic Pedagogical Competence?" In The profession of Teacher in Dutch Educational Praxis, edited by Jan Ax, and Petra Ponte, 129-144. Amsterdam: Sense Publishers.

Yang, Min. 2009. "Making Interdisciplinary Subjects Relevant to Students: An Interdisciplinary Approach." Teaching in Higher Education 14(6): 597606. 